\title{
LABORATORY ASSAYS FOR SELECTION OF BOTRYTIS SUPPRESSIVE MICRO-ORGANISMS ON NECROTIC GRAPE LEAF DISCS
}

\author{
M. WALTER ${ }^{1}$, S.M. ZYDENBOS ${ }^{2}$, M.V. JASPERS ${ }^{3}$ and A. STEWART ${ }^{3}$ \\ ${ }^{1}$ HortResearch, P.O Box 51, Lincoln, New Zealand \\ ${ }^{2}$ Old West Coast Road, Halkett RD 1, Christchurch, New Zealand \\ ${ }^{3}$ National Centre for Advanced Bio-Protection Technologies, PO Box 84, \\ Lincoln University, Canterbury, New Zealand
}

Corresponding author: mwalter@hortresearch.co.nz

\begin{abstract}
Isolates of saprophytic fungi $(\mathrm{n}=209)$ were evaluated for biological control potential against Botrytis cinerea using in vitro dual plate and necrotic grape leaf disc assays. Interrupted wetness periods were introduced during the 40-day assay to select for disease suppressive saprophytic fungi with a high tolerance to fluctuating dry and wet periods. Leaf disc assays were highly reproducible, with relative rankings of the test isolates being similar over three assays. In the absence of antagonists, $B$. cinerea sporulation increased during the 40-day incubation to cover over $90 \%$ of the leaf disc area in conidiophores. However, in the presence of antagonists, B. cinerea sporulation was heavily reduced, with the top seven isolates having less than $10 \%$ coverage relative to the control. Thirteen isolates representing four genera, Alternaria spp., Epicoccum spp., Trichoderma spp. and Ulocladium spp., have been identified for further laboratory testing prior to selection of a limited number of isolates for field evaluation.

Keywords: Epicoccum, Alternaria, Trichoderma, Ulocladium, biological control, grape, leaf disc assays.
\end{abstract}

\section{INTRODUCTION}

Bunch rot disease of grapes, caused by Botrytis cinerea Pers., can cause serious pre- and postharvest crop losses and affect the quality of wine produced from infected grapes. Flower infections via the receptacle are an important pathway for $B$. cinerea grape infections (Viret et al. 2004), as is flowering debris trapped within the bunches (Elmer \& Michailides 2004). While control of the pathogen has traditionally relied on fungicides, other options are required because of fungicide resistance (Leroux et al. 2002) and consumer demand for pesticide-free products. One alternative is a biocontrol agent that would survive in the phylloplane, and colonise, compete and/or displace $B$. cinerea in order to suppress the disease inoculum potential and/or infections (Köhl 2004).

There are a number of reports of micro-organisms with antagonism towards Botrytis spp., including the fungal genera Alternaria, Cladosporium, Epicoccum, Gliocladium, Trichoderma and Ulocladium, and this subject has been reviewed by Elad \& Stewart (2004). Generally, to identify potentially antagonistic micro-organisms, a suitable screening assay is required. Although, by necessity, such an assay will be based in the laboratory, it must approximate conditions encountered in the field, such as development on plant tissue and periods of moisture stress. Köhl et al. (1995a, b; 1997) have developed such protocols for screening potential biocontrol agents on onion and lily leaf sections in vitro. 
This paper describes laboratory assays that were used to screen micro-organisms for antagonism towards $B$. cinerea on necrotic grape leaf discs. The aim was to develop a repeatable assay that mimicked field conditions, so extended incubation times were tested and interrupted wetness periods were included in the experiment.

\section{Isolates}

\section{MATERIALS AND METHODS}

All saprophytic test isolates $(n=209)$ were obtained from the Lincoln University or HortResearch culture collections and originated from bioprospecting of New Zealand's vineyards $(n=107)$ or kiwifruit orchards $(n=102)$. The latter group of saprophytic fungi were selected in HortResearch's Biological Control research programme, which screened commonly occurring saprophytes for their ability to suppress B. cinerea development in kiwifruit (Elmer et al. 1997). The 107 vineyard isolates were sourced from organic and conventional vineyards, by sampling various necrotic tissues, green leaves and canes of grapes, as well as other plants and mushrooms. The test micro-organisms represented nine genera, Alternaria, Cladosporium, Epicoccum, Gliocladium, Trichoderma, Ulocladium, Aureobasidium, Cryptococcus and Saccharomyces, and included six unidentified microorganisms. Botrytis cinerea isolates B1, B2, B4 and B7, originally from grapes, were obtained from Lincoln University (Fowler et al. 1999). All micro-organisms were stored on potato dextrose agar (PDA, Oxoid) slopes at $4^{\circ} \mathrm{C}$.

Mycelial inoculum (for the dual plate assay) was produced by growing isolates on PDA at $20^{\circ} \mathrm{C}$ in the dark until hyphae reached the margin of the Petri dish. Conidial inoculum (for the necrotic leaf disc assays) was produced by modifying the method of Köhl et al. (1999). Briefly, B. cinerea isolates and test micro-organisms were grown on oatmeal agar (OMA, $30 \mathrm{~g} /$ litre of Fleming's oatmeal and $20 \mathrm{~g} /$ litre of Oxoid agar) at $20^{\circ} \mathrm{C}$ and $12 \mathrm{~h}$ photoperiod for 14 days and the spores washed off in sterile distilled water plus $0.05 \%$ Tween 80 (Tween water). Conidial suspensions were then washed three times in Tween water and collected by centrifugation $(2 \mathrm{~min}$ at $1500 \times g)$. The conidial density was determined with a haemocytometer (Neubauer, Germany) and adjusted with Tween water to $10^{6}$ conidia/ml for test micro-organisms, except for isolates of Cladosporium, Gliocladium, Trichoderma and yeast species, which were tested at conidial concentrations of $10^{7}-10^{8}$ conidia/ml (Köhl et al. 1995a, 1995b). Botrytis cinerea isolates B1, B2, B4, and B7 were adjusted to $10^{4}$ conidia/ml and combined in equal proportions to obtain a mixed Botrytis inoculum.

\section{Dual plate assay}

The 107 test isolates from New Zealand vineyards were screened for in vitro inhibition of mycelial growth of B. cinerea isolate B1, adopting the basic methodology from Köhl et al. (1997). Mycelial inoculum (10 mm plugs) was cut using a cork borer from the leading edge of a colony. One plug each of $B$. cinerea $\mathrm{B} 1$ and a test isolate were placed $50 \mathrm{~mm}$ apart in an $85 \mathrm{~mm}$ diameter Petri dish containing PDA. Four replicate plates were prepared for each pathogen-test isolate combination. The plates were incubated at $20^{\circ} \mathrm{C}$ with a $12 \mathrm{~h}$ photoperiod and assessed visually after 15 and 30 days using a scale of 1-4 as follows:

1 Test isolate overgrown by pathogen

2 Both cultures stopped upon or just prior to contact

3 Display of zone of inhibition

4 Pathogen overgrown by test isolate

The sum of the scores recorded from the two assessment dates and the four replicates was used as an index indicating the likelihood of antagonistic interaction (minimum score $=8$; maximum score $=32$ ). The 21 test isolates that scored values equal to or greater than 16 were considered as potentially antagonistic and were selected for further studies in the necrotic leaf disc assay. 


\section{Necrotic leaf disc assay over 8 days}

Saprophytic fungi $(\mathrm{n}=102)$ previously identified as having antagonistic activity towards B. cinerea on necrotic kiwifruit leaf tissue (Elmer et al. 1997) and isolates from the dual plate assay $(n=21)$ were used. Competitive interactions between the test micro-organisms and the pathogen were conducted on necrotic leaf discs adopting the methods of Köhl et al. (1995a, b).

Mature leaves from Chardonnay UDC5 were collected from the Lincoln University experimental vineyard. Leaf discs ( $25 \mathrm{~mm}$ diameter) were cut with a cork borer, avoiding all damaged and necrotic leaf tissue. Leaf discs were washed (10 min under running tap water), allowed to soak for $2 \mathrm{~h}$ and then rinsed again (10 min running tap water) prior to drying $\left(50^{\circ} \mathrm{C}\right)$ in a single layer pressed between cardboard sheets for $10 \mathrm{~h}$. Dry leaf discs were packed in $200 \mathrm{ml}$ specimen containers (Labserv), $\boldsymbol{\gamma}$ - irradiated with cobalt (25 kiloGy for $6.8 \mathrm{~min}$ at Mallinckrodt Veterinary Ltd, Upper Hutt), and stored at ambient temperature in the dark.

Four sterile leaf discs were placed in an $85 \mathrm{~mm}$ diameter Petri dish on top of two sterile filter papers ( $70 \mathrm{~mm}$ diameter, Whatman No. 1) and re-hydrated with $2.2 \mathrm{ml}$ sterile distilled water at $4^{\circ} \mathrm{C}$ in the dark for $24 \mathrm{~h}$. Rehydrated leaf discs were inoculated with the mixed $B$. cinerea spore suspension $\left(10^{4}\right.$ conidia/ml $)$ by spraying the inoculum evenly across the plates at a rate of $0.5 \mathrm{ml} /$ plate using an airbrush (Badger, model 250-2, USA) and propellant (1,1-difluoroethane and butane mix; Badger) at a distance of approximately $350 \mathrm{~mm}$ from the surface. Petri dishes were covered in plastic wrap, randomly arranged and incubated for $8 \mathrm{~h}$ in the dark at $20^{\circ} \mathrm{C}$. After incubation, spore suspensions of the test isolates, iprodione ( $2 \mathrm{ml} /$ litre Rovral ${ }^{\mathrm{TM}}$ Flo, Rhone-Poulenc New Zealand Ltd, $25 \%$ active ingredient) or sterile distilled water for the control were applied at $0.5 \mathrm{ml} / \mathrm{plate}$ following the procedure for $B$. cinerea application. There were five replicate plates for each treatment and 20 replicate plates for the water control. The Petri dishes were re-covered in plastic wrap, randomly arranged and further incubated $(12 \mathrm{~h})$ at $20^{\circ} \mathrm{C}$ in the dark. After $12 \mathrm{~h}$ incubation, leaf discs were moved into new sterile Petri dishes lined with a single dry filter paper. To simulate an interrupted wetness period (Köhl et al. 1995b), lids were removed and leaf discs were dried $\left(25-27^{\circ} \mathrm{C}, 6 \mathrm{~h}\right)$ under gentle airflow in the laminar flow cabinet. Leaf discs were then rehydrated with $1.7 \mathrm{ml}$ sterile distilled water. Petri dishes were sealed with plastic wrap, randomly arranged and incubated at $20^{\circ} \mathrm{C}$ and $12 \mathrm{~h}$ photoperiod for 7 days, giving a total incubation time of 8 days.

Sporulation of $B$. cinerea on the leaf discs was assessed visually under the microscope $(\times 20)$. The percentage area of the leaf discs covered densely with conidiophores of $B$. cinerea was estimated using points of $0,1,5,10,25,50,75,90$ or $100 \%$, where $0 \%$ indicated no $B$. cinerea sporulation and $100 \%$ indicated complete coverage (Whiteman $\&$ Stewart 1998). The mean value for $B$. cinerea coverage of the four leaf discs in each Petri dish was calculated and expressed as a percentage of the mean $B$. cinerea coverage for the water control leaf discs to give a relative coverage value. The complete assay of the 123 test isolates, iprodione treatment and water control (4 leaf discs/Petri plate and 5 Petri plates/treatment) was carried out twice (Test 1 and Test 2) to assess reproducibility.

\section{Necrotic leaf disc assay over 40 days}

Based on the initial 8-day necrotic leaf disc assays, 36 isolates were identified as potentially antagonistic to $B$. cinerea. All isolates were tested at $10^{6} \mathrm{conidia} / \mathrm{ml}$ except for one Gliocladium sp. and the five Trichoderma spp. isolates that were also tested at $10^{8}$ conidia $/ \mathrm{ml}$. These selected micro-organisms were re-screened in an extended assay, where four additional dry periods or interrupted wetness periods, each lasting $72 \mathrm{~h}$, were imposed on day $8,16,24$ and 32, after estimates of $B$. cinerea leaf coverage had been made. The additional interrupted wetness periods consisted of removing the plastic wrap from the Petri dishes and allowing the discs to dry slowly in the incubator resulting in an average evaporation rate of $0.2 \mathrm{ml} / \mathrm{h} /$ Petri dish. Following each interrupted wetness period, the filter paper in the Petri dishes was re-hydrated with $1.7 \mathrm{ml}$ sterile distilled water per Petri dish and the dishes were re-covered in plastic wrap. A final assessment of $B$. cinerea sporulation was made after 40 days. 


\section{Statistical analysis}

The data were examined by analysis of variance (ANOVA) and Fisher's Least Significant Difference Test (LSD) using the statistical software package SYSSTAT 6 (Systat Software, Inc., Point Richmond, USA).

\section{RESULTS}

\section{Dual plate assay}

Only four test isolates (two Epicoccum spp., one Trichoderma sp. and one unidentified micro-organism) completely overgrew the pathogen (corresponding to a single-plate score of 4) for at least two replicate plates after 30 days in the dual plate assay. None of the 107 vineyard isolates tested displayed a zone of inhibition (corresponding to a single-plate score of 3) for any replicates after either incubation period. Nonetheless, the sum of the combined scores from both assessments was equal to or greater than 16 for 21 isolates. For these isolates, the antagonist and pathogen culture stopped upon or just prior to contact (corresponding to a single-plate score of 2) or the antagonist overgrew the pathogen. These 21 isolates therefore were considered as potentially antagonistic and worthy of further testing. These were four isolates of Alternaria spp. (A13, A14 and A15 from necrotic grape leaves, organic vineyard; and A17 from a fresh grape leaf, organic vineyard), seven isolates of Cladosporium spp. (C08 and C10 from necrotic grape leaves, organic vineyard; $\mathrm{C} 11$ and $\mathrm{C} 12$ from fresh grape tissue, organic vineyard; and C13, C18 and C19 from fresh grape tissue, conventional vineyard), six isolates of Epicoccum spp. (E13, E14, E15 and E19 from necrotic grape leaves, organic vineyard; and E20 and E21 from fresh grape leaves, organic vineyard), one Trichoderma sp. (T19 from Agaricus campestris L.: Fr., organic vineyard), two unidentified yeasts (UY01 and UY02 from fresh grape leaves, conventional vineyard) and an unidentified micro-organism (UM01 from a fresh grape leaf, conventional vineyard).

\section{Necrotic leaf disc assay over 8 days}

The control plates had a mean B. cinerea sporulation coverage of $51 \%$ and $48 \%$ after 8 days for Test 1 and Test 2, respectively. Of the 123 isolates tested, 105 did not result in significantly different $B$. cinerea sporulation between the two tests $(P>0.05)$. This indicates that overall there was a high level of reproducibility between the two tests. Therefore, the data from Test 1 and Test 2 were pooled for the following results.

Botrytis cinerea sporulation, expressed in mean relative coverage values, ranged from $9 \%$ to $133 \%$ for the 123 isolates after 8 days. A total of 36 isolates reduced $B$. cinerea sporulation by at least $60 \%$ (or equivalent to a relative coverage value below $40 \%$ ) and were used in further tests. These comprised 12 Alternaria spp., eight Epicoccum spp., one Gliocladium sp., five Trichoderma spp. and 10 Ulocladium spp. The isolate with the lowest $B$. cinerea mean relative coverage was Epicoccum sp. E21 (9\%). The mean relative sporulation for the iprodione treatment was $4 \%$.

\section{Necrotic leaf disc assay over $\mathbf{4 0}$ days}

Results for the 36 isolates for the first assessment after 8 days were highly reproducible. Although, the relative measurements of $B$. cinerea sporulation at 8 days tended to be higher in the initial 8-day than the 40-day necrotic leaf disc assay, the relative rankings of the micro-organisms at 8 days were very similar between the two assays (partially demonstrated by data in Table 1). After 8 days incubation the control plates had a mean B. cinerea sporulation coverage of $50 \%$, which was the same $(\mathrm{P}>0.05)$ as the 8 -day necrotic leaf disc assay. Botrytis cinerea sporulation continued to increase $(\mathrm{P}<0.05)$ as the incubation period was extended (Table 1). This increase in $B$. cinerea sporulation (Y) in the control treatment followed a quadratic regression curve over time (x), with B. cinerea sporulation $\mathrm{Y}_{(\% \text { actual area) }}=3.4+6.1 \mathrm{x}-0.1 \mathrm{x}^{2}\left(\mathrm{R}^{2}=0.984 ; \mathrm{P}=0.002\right)$. The mean relative sporulation for the iprodione treatment was $10 \%$ after 8 days. This was higher $(\mathrm{P}<0.05)$ than in the 8-day necrotic leaf disc assay experiment $(4 \%)$. For the iprodione treatment, $B$. cinerea sporulation also continued to increase $(\mathrm{P}<0.05)$ over the remainder of the experiment (Table 1). 
TABLE 1: Mean leaf coverage by $B$. cinerea for the control (actual \%) and for 13 isolates and iprodione (relative \%) after 8, 16, 24, 32 and 40 days of incubation in the 40-day necrotic leaf disc assay. Data shown are for isolate concentrations of $10^{6}$ conida/ $/ \mathrm{ml}$, except for Trichoderma spp. where concentrations were $10^{8}$ conidia/ml.

\begin{tabular}{|c|c|c|c|c|c|c|c|}
\hline & \multicolumn{5}{|c|}{ Incubation period (days) } & \multirow[b]{2}{*}{$\mathrm{LSD}^{2}$} & \multirow{2}{*}{$\begin{array}{l}\text { Overall } \\
\text { mean }^{3}\end{array}$} \\
\hline & 8 (Initial) $^{1}$ & 16 & 24 & 32 & 40 & & \\
\hline Control & $50 \quad(49)$ & 80 & 89 & 92 & 93 & 5 & 81 \\
\hline Iprodione & 10 (4) & 40 & 77 & 93 & 98 & 10 & 63 \\
\hline Trichoderma sp. T16 & $6(21)$ & 2 & 1 & 1 & 1 & 4 & 2 \\
\hline Epicoccum sp. E21 & $14(9)$ & 5 & 1 & 0 & 0 & 8 & 4 \\
\hline Trichoderma sp. T19 & $13(13)$ & 9 & 4 & 3 & 3 & 7 & 6 \\
\hline Trichoderma sp. T13 & $13(25)$ & 8 & 8 & 6 & 7 & 4 & 8 \\
\hline Epicoccum sp. E18 & $13(15)$ & 9 & 7 & 5 & 6 & 5 & 8 \\
\hline Epicoccum sp. E10 & $14(22)$ & 8 & 9 & 6 & 6 & 6 & 8 \\
\hline Ulocladium sp. U16 & $19(35)$ & 10 & 4 & 3 & 3 & 8 & 8 \\
\hline Epicoccum sp. E09 & $10(36)$ & 9 & 13 & 8 & 7 & 6 & 10 \\
\hline Epicoccum sp. E26 & $20(20)$ & 12 & 11 & 10 & 9 & 7 & 12 \\
\hline Ulocladium sp. U09 & $14(28)$ & 19 & 18 & 22 & 17 & 10 & 18 \\
\hline Alternaria sp. A04 & $41(28)$ & 26 & 16 & 11 & 3 & 13 & 19 \\
\hline Ulocladium sp. U13 & $26(36)$ & 26 & 28 & 12 & 8 & 14 & 20 \\
\hline Alternaria sp. A03 & $30(25)$ & 31 & 22 & 13 & 6 & 11 & 20 \\
\hline $\mathrm{LSD}^{4}$ & 27 (29) & 19 & 17 & 15 & 14 & & 35 \\
\hline
\end{tabular}

${ }^{1}$ Results from the initial 8-day leaf disc assay experiments (Test 1\&2) are shown in ().

${ }^{2} \mathrm{LSD}$ at $\mathrm{P}<0.05$, separating means in each row (excluding the initial leaf disc assay experiment).

${ }^{3}$ Values are the mean for measurements made at 8, 16, 24, 32 and 40 days.

${ }^{4} \mathrm{LSD}$ at $\mathrm{P}<0.05$, separating treatment/test isolate in each column (excluding Control).

Of the 36 isolates tested, 24 reduced $(\mathrm{P}<0.05)$ B. cinerea sporulation over time, with 13 saprophytes showing an overall suppression in B. cinerea sporulation of $20 \%$ or less (based on the overall mean) as shown in Table 1. These 13 micro-organisms representing four genera, Alternaria spp., Epicoccum spp., Trichoderma spp. and Ulocladium spp., have been identified for further laboratory testing prior to selection of a limited number of isolates for field evaluation. For one test isolate (U09) B. cinerea sporulation increased $(\mathrm{P}<0.05)$ over time and for the remaining 11 isolates, there was no significant change $(\mathrm{P}>0.05)$ in mean relative coverage values over time. Three isolates (E21, T19 and E18) that had ranked in the top six isolates in the initial 8-day leaf disc assay experiment were among the top seven isolates in this experiment, based on both the 8-day result as well as the overall mean (Table 1).

\section{DISCUSSION}

As a necrotrophic pathogen, $B$. cinerea readily colonises dead or senescing tissues on which it can sporulate. Suppression of sporulation therefore may be a useful tool in B. cinerea inoculum management and subsequent disease control (Fokkema 1993). The bioassay method, therefore, was chosen to select for antagonistic fungi on dead/necrotic tissue (Köhl et al. 1995a).

In the initial 8-day necrotic leaf disc assay, the similarity between Test 1 and Test 2 indicated very good reproducibility, and therefore it was considered a suitable assay for identifying potentially antagonistic micro-organisms. However, to test the isolates under 
conditions approximately the field situation (Köhl et al. 1995a, b), the conditions were altered to introduce a greater incubation time that included periods of drying or moisture stress. Overall, disease suppression or control of $B$. cinerea sporulation on necrotic grape leaf tissue was consistent and reproducible for the top 13 of the 36 saprophytes tested in Test 1 and Test 2, as well as in the 40-day assay. The method was reliable in terms of showing distinct reductions in $B$. cinerea sporulation and detecting differences between test isolates. The advantages and disadvantages of the bioassay method using necrotic leaf tissue have been thoroughly discussed by Köhl et al. (1995a). The necrotic tissue method has been successfully employed to select an Ulocladium atrum G. Preuss (isolate 385 ) biocontrol agent suitable for $B$. cinerea control in strawberry, cyclamen, grapes and rose as reviewed by Köhl (2004).

In the 40-day assay, $B$. cinerea sporulation increased in the absence of antagonistic micro-organisms, in a quadratic fashion over time. The iprodione treatment was initially effective at reducing B. cinerea sporulation, being $20 \%$ of the control at 8 days and $50 \%$ of the control at 16 days. However, after 24 days, when the fungicide had presumably broken down, there was little difference in $B$. cinerea sporulation between the iprodione treatment and the control. For all the 13 test isolates shown in Table 1 there was a trend for reducing sporulation over the 40 days of the assay, indicating competitive suppression by the antagonists. Future research should include experiments that identify the nature of the competition between the micro-organisms as this information may help with maximising effectiveness in the field.

It is noteworthy that a greater number of saprophytes were found in vineyards under organic than conventional production. This is in agreement with research by Waipara et al. (2002), who studied the differences in microbial populations (culturable epiphytes) between organic and conventional apple orchards in New Zealand. They reported that irrespective of site and grower, more micro-organisms (in terms of total numbers and species present) were found in organic than conventional apple orchards. Epicoccum sp. E21 was ranked first or second in all experiments and had originally been isolated from fresh organically grown grape leaf material during the initial bioprospecting from vineyards. Of the 107 micro-organisms originally isolated from vineyards, 24 showed antagonistic potential in the dual plate assay. However, only three of the vineyardcollected micro-organisms (E21, T19 and A15) were among the top 36 isolates in the initial 8-day necrotic leaf disc assay and only E21 was listed in the top 13 isolates for the 40-day necrotic leaf disc assay.

In conclusion, 13 saprophytic fungal isolates have been identified as potentially antagonistic to $B$. cinerea on necrotic grape leaf discs. Since field testing of biocontrol micro-organisms is an expensive undertaking, before proceeding to this step it is recommended that further laboratory testing be carried out. This would enable additional conditions to be tested, such as changing the amount of pathogen inoculum applied to the leaf discs or increasing the number of pathogen challenges. In addition, further laboratory experimentation would give scope to reduce the number of isolates being tested in the field.

\section{ACKNOWLEDGEMENTS}

This project was funded by Winegrowers of New Zealand Limited and the New Zealand Foundation for Research, Science and Technology. The experiments were conducted by Adrian Antonov (formerly of Lincoln University). We gratefully acknowledge Jürgen Köhl, IPO-DLO Wageningen, The Netherlands, for advice in developing laboratory based screening methods. Thanks to Mike Trought (formerly of Lincoln University), Philip Elmer (HortResearch) and Peter Wood (HortResearch) for discussions and feedback; and to Chris Frampton (Otago School of Medicine) for statistical analyses. 


\section{REFERENCES}

Elad Y, Stewart A 2004. Microbial control of Botrytis spp. In: Elad Y, Williamson B, Tudzynski P, Delen N ed. Botrytis: Biology, pathology and control. Kluwer, Dordrecht, The Netherlands. Pp. 223-241.

Elmer PAG, Walter M, Perry JH, Boyd-Wilson KSH, Virgin-Harris T, Morgan C, McNaughton C 1997. Biological suppression of botrytis in kiwifruit-will it work?' HortResearch Special Publication - Towards Natural Solutions. HortResearch, Palmerston North, New Zealand.

Elmer PAG, Michailides TM 2004. Epidemiology of Botrytis cinerea in orchard and vine crops. In: Elad Y, Williamson B, Tudzynski P, Delen N ed. Botrytis: Biology, pathology and control. Kluwer, Dordrecht, The Netherlands. Pp. 243-272.

Fokkema NJ 1993. Opportunities and problems of control of foliar pathogens with micro-organisms. Pesticide Science 37: 411-416.

Fowler SR, Jaspers MV, Walter M, Stewart A 1999. Suppression of overwintering Botrytis cinerea inoculum on grape rachii using antagonistic fungi. New Zealand Plant Protection 52: 141-147.

Köhl J 2004. Biological control of Botrytis spp. by Ulocladium atrum through competitive colonisation of necrotic plant tissues. Plant Research International B.V., Wageningen, The Netherlands.

Köhl J, Belanger RR, Fokkema NJ 1997. Interaction of four antagonistic fungi with Botrytis aclada in dead onion leaves - a comparative microscopic and ultrastructural study. Phytopathology 87: 634-642.

Köhl J, van der Plas CH, Molhoek WML, Fokkema NJ 1995a. Effect of interrupted leaf wetness periods on suppression of sporulation of Botrytis allii and B. cinerea by antagonists on dead onion leaves. European Journal of Plant Pathology 101: 627-637.

Köhl J, Molhoek WML, van der Plas CH, Fokkema NJ 1995b. Effect of Ulocladium atrum and other antagonists on sporulation of Botrytis cinerea on dead lily leaves exposed to field conditions. Phytopathology 85: 393-401.

Köhl J, Lombaers-van der Plas CH, Molhoek WML, Kessel GJT, Goossen-van der Geijn HM 1999. Competitive ability of the antagonist Ulocladium atrum and Gliocladium roseum at temperatures favourable for Botrytis spp. development. BioControl 44: 329-346.

Leroux P, Fritz R, Debieu D, Albertini C, Lanen C, Bach J, Gredt M, Chapeland F, Hollomon DW 2002. Mechanisms of resistance to fungicides in the field strains of Botrytis cinerea. Pest Management Science 58: 876-888.

Viret O, Keller M, Jaudzems G, Cole FM 2004. Botrytis cinerea infection of grape flowers: Light and electron microscopical studies of infection sites. Phytopathology 94 (8): 850-857.

Waipara NW, Obanor FO, Walter M 2002. Impact of phylloplane management on microbial populations. New Zealand Plant Protection 55: 125-128.

Whiteman SA, Stewart A 1998. Suppression of Botrytis cinerea sporulation on irradiated grape leaf tissues by the antagonistic bacterium Serratia liquefaciens. New Zealand Journal of Crop and Horticultural Science 26: 325-330. 